\title{
Comparative Assessment of Factors Involved in Acetoin Synthesis by Bacillus subtilis 168
}

\author{
Pratibha Sharma ${ }^{1}$ and Santosh Noronha ${ }^{2}$ \\ ${ }^{1}$ Department of Bioscience and Bioengineering, Indian Institute of Technology Bombay, Powai, Mumbai 400076, India \\ ${ }^{2}$ Department of Chemical Engineering, Indian Institute of Technology Bombay, Powai, Mumbai 400076, India
}

Correspondence should be addressed to Santosh Noronha; noronha@iitb.ac.in

Received 13 January 2014; Accepted 6 February 2014; Published 10 March 2014

Academic Editors: G. Koraimann and T. P. West

Copyright (C) 2014 P. Sharma and S. Noronha. This is an open access article distributed under the Creative Commons Attribution License, which permits unrestricted use, distribution, and reproduction in any medium, provided the original work is properly cited.

\begin{abstract}
Acetoin is widely used as flavor agent and serves as a precursor for chemical synthesis. Here we focused on identifying the best physiological conditions (initial substrate concentrations, $\mathrm{pH}$, temperature, and agitation) for enhanced acetoin accumulation by Bacillus subtilis 168. The optimal physiological conditions support maximum acetoin accumulation by minimizing byproduct (acetate and butanediol) synthesis and a maximum of 75\% enhancement in acetoin yield could be achieved. Additionally, the effect of change in ALS (acetolactate synthase) and ALDC (acetolactate decarboxylase) activities was evaluated on acetoin accumulation. Increasing ALS and ALDC enzyme activities led to efficient utilization of pyruvate towards acetoin accumulation and about $80 \%$ enhancement in acetoin accumulation was observed.
\end{abstract}

\section{Introduction}

Acetoin is a four-carbon hydroxy-keto compound that is secreted by various microorganisms when grown on glycolytic substrates. It is widely used in the food and dairy industry as a preservative [1]. Acetoin has two biological analogues, diacetyl and 2,3-butanediol. The ratio of these metabolites present depends on the culture redox potential [2].

Acetoin is a secondary carbon source synthesized during sporulation in various organisms such as Bacillus subtilis $[3,4]$, Klebsiella terrigena [5], and Pelobacter carbinolicus [6]. In Bacillus subtilis, acetoin synthesis involves alsSD operon that consists of alsS and als $D$ genes encoding for acetolactate synthase (ALS; E.C. 2.2.1.6) and acetolactate decarboxylase (ALDC; E.C. 4.1.1.5), respectively [3]. However, in Klebsiella and Pelobacter sp., a butanediol dehydrogenase $(b d h)$ is integrated with alsSD operon that leads to production of 2,3butanediol as major product instead of acetoin. Therefore, Bacillus subtilis is used as a model organism for study of acetoin synthesis.

A number of factors can affect the fate of metabolites by diverse alternative metabolic pathways [7]. Among them, initial substrate concentration $[8,9]$, temperature [10], $\mathrm{pH}$ [11], and oxygen levels [12] are known to affect secondary metabolites production in Klebsiella and Pelobacter sp. To our knowledge, no report exists on the assessment of these physiological factors and activities of acetoin synthesis enzymes (ALS and ALDC) for acetoin accumulation by B. subtilis.

Our current interest focuses on identification of important variables to enhance acetoin accumulation and minimizing byproduct formation. For this purpose, we focused on two effects. First, we focus on the systematic evaluation of physiological factors (initial substrate concentration, temperature, $\mathrm{pH}$, and aeration) on growth and acetoin production. Second, we investigated the effect of ALS and ALDC enzyme activities on metabolites (glucose, pyruvate, acetate, acetoin, and 2,3butanediol) accumulation patterns.

\section{Materials and Methods}

2.1. Media, Growth Conditions, and Maintenance. A list of strains with their genotype description is provided in Table 1. B. subtilis and E. coli cultures were grown in Luria Bertani (Hi Media Laboratories Pvt. Ltd., Mumbai, India) medium 
TABLE 1: List of plasmid, strains, and their sources.

\begin{tabular}{lcc}
\hline Plasmids/strain & Genotype description & Source \\
\hline pHCMC & E. coli, Bacillus shuttle vector, Cam ${ }^{\mathrm{r}}$, Ap $^{\mathrm{r}}$ & BGSC $^{*}$ \\
pHCMC-alsSD & alsSD $(2.5 \mathrm{~Kb})$ operon cloned at BamH1 and XbaI site of pHCMC05 & Lab stock \\
Bacillus subtilis 168 & $\operatorname{trpC2}$ & BGSC $^{*}$ \\
BS7431 & $\operatorname{trpC2}$ pHCMC & Lab stock \\
BS7432 & $\operatorname{trpC2}$ pHCMalsSD & Lab stock \\
BSIP1194 & trpC2 alsR::cam & {$[14]$} \\
\hline
\end{tabular}

${ }^{*}$ Bacillus Genetic Stock Center.

at $37^{\circ} \mathrm{C}$ and shaking at $200 \mathrm{rpm}$. Bacillus subtilis was also grown in Tris base medium (TSS) [13]. Unless stated, $10 \mathrm{~g} / \mathrm{L}$ of glucose was used for growth studies. When required, ampicillin $(100 \mu \mathrm{g} / \mathrm{mL})$ and chloramphenicol $(25 \mu \mathrm{g} / \mathrm{mL})$ were used for selection of $E$. coli strains (Sigma Chemical Co., USA). Chloramphenicol $(5 \mu \mathrm{g} / \mathrm{mL})$ was used for selection of Bacillus strains.

Unless otherwise mentioned, all chemicals were purchased from Sisco Research Laboratory Pvt. Ltd., Mumbai, India. Standard cloning protocols were followed in Escherichia coli and Bacillus subtilis, as described in Sambrook et al., 1989, and Harwood and Cutting, 1990, respectively.

2.2. Acetolactate Synthase Assay. For preparation of crude lysates, a single colony of BS7431 and BS7432 was transferred into $10 \mathrm{~mL} \mathrm{LB}$ with appropriate antibiotic and incubated at $37^{\circ} \mathrm{C}$ for 16 hrs. $1 \mathrm{~mL}$ of this culture was transferred into $100 \mathrm{~mL}$ of $\mathrm{LB}$ in a $500 \mathrm{~mL}$ flask and was incubated at $37^{\circ} \mathrm{C}$ till an $\mathrm{OD}_{600} \sim 0.1$. From each flask, $10 \mathrm{~mL}$ of the culture was aliquoted into each of 6 test tubes. In three of these tubes cultures were induced using $3 \mathrm{mM}$ IPTG; the rest were used as control. After $6 \mathrm{hrs}$ of incubation at $37^{\circ} \mathrm{C}$, cells were pelleted down by centrifugation at $16000 \mathrm{~g}$ for $5 \mathrm{~min}$ (Hettich Zentrifugen, Micro 220R). Pellets were dissolved in a buffer containing 0.05 M HEPES (Sigma Chemical Co., USA) and $0.1 \mathrm{M} \mathrm{KCl}$. For lysis, $1 \mathrm{mg}$ of lysozyme and $10 \mu \mathrm{L}$ of protease inhibitor cocktail (Fermentas, USA) were then added and the mixture was incubated for $1 \mathrm{hr}$ at $4^{\circ} \mathrm{C}$. To rupture cells, 1520 cycles of sonication with 30 seconds pulses (at 30 -second intervals) were performed (Branson, Model 250). Sonicated samples were then centrifuged for $45 \mathrm{~min}$ at $16000 \mathrm{~g}$ to remove cell debris. For storage, $25 \%$ of glycerol was added to the supernatant.

The ALS activity assay was performed as per Holtzclaw et al., 1975, with some modifications. The reaction mixture for this assay contained $100 \mathrm{mM}$ of $\mathrm{K}_{2} \mathrm{HPO}_{4} \mathrm{pH} 7.0,20 \mu \mathrm{M}$ potassium pyruvate (Sigma Chemical Co., USA), $10 \mu \mathrm{M} \mathrm{MgCl}$, and $80 \mu \mathrm{g} / \mathrm{mL}$ TPP (Himedia Laboratories Pvt. Ltd., Mumbai, India). The reaction was initiated on addition of $0.1 \mathrm{~mL}$ crude lysate and incubated for $15 \mathrm{~min}$ at $37^{\circ} \mathrm{C}$. The reaction was terminated with $0.1 \mathrm{~mL}$ of $8 \mathrm{~N} \mathrm{H}_{2} \mathrm{SO}_{4}$ (E. Merck, India). As a control, the crude lysate was added after the addition of $\mathrm{H}_{2} \mathrm{SO}_{4}$. The reaction mixtures were centrifuged for $25 \mathrm{~min}$ at $16000 \mathrm{~g}$ to precipitate the protein. The supernatant was incubated for $30 \mathrm{~min}$ at $37^{\circ} \mathrm{C}$. $0.5 \mathrm{~mL}$ of supernatant was transferred to $0.1 \mathrm{M}$ creatine and $\alpha$-naphthol solution [15]. The reaction mixture was then incubated at $37^{\circ} \mathrm{C}$ for $10 \mathrm{~min}$ and the absorbance was measured at $540 \mathrm{~nm}$. An enzyme unit is a measure of synthesis of 1 mole of acetoin. Specific activity of ALS was measured as the enzyme activity per milligram of total protein.

2.3. Cultivation Experiments. The wild-type and recombinant strains of Bacillus subtilis 168 were inoculated in LB $(10 \mathrm{~mL})$ and grown overnight at $37^{\circ} \mathrm{C}$ and $200 \mathrm{rpm} .1 \mathrm{~mL}$ of this overnight culture was pelleted down and washed with $0.1 \mathrm{M}$ phosphate buffer saline. This washed pellet was used to inoculate $100 \mathrm{~mL}$ of TSS medium containing the desired carbon concentration and $\mathrm{pH}$ conditions as required for specific experiments. Samples for measurement of OD and metabolite were taken at $5 \mathrm{hr}$ intervals until the glucose was exhausted and utilization of acetoin had started. Where required, cells were induced on addition of $3 \mathrm{mM}$ IPTG (Fermentas, USA) at $\mathrm{OD}_{600} \sim 0.2$. Metabolite concentrations were measured immediately without storing samples.

Estimation of glucose, pyruvate, acetate, acetoin, and 2,3butanediol concentrations was carried out on an HPLC using Bio-Rad Aminex HPX-87H ion exclusion column of $300 \mathrm{~mm}$ $\times 7.8 \mathrm{~mm} .5 \mathrm{mM} \mathrm{H}_{2} \mathrm{SO}_{4}$ was used as the mobile phase and column temperature was maintained at $65^{\circ} \mathrm{C}$.

The results presented in this work are from 3-5 independent experiments, performed in triplicate.

\section{Results and Discussions}

3.1. Identification of Optimal Glucose Levels. The glucose levels present during growth of $B$. subtilis are thought to affect acetoin synthesis in two ways. First, an increase in glucose concentration leads to an increase in glycolytic flux towards acetoin synthesis and consequently an increase in acetoin accumulation may be observed $[8,9]$. Second, acetoin synthesis is under catabolite repression [16, 17], and consequently a high glucose concentration (0.5\%) represses acetoin synthesis [16]. Therefore, it is important to optimize the glucose concentration for efficient acetoin accumulation. Towards this objective, Bacillus subtilis 168 was grown in TSS media provided with $2.5,5.0,10.0,20.0,50.0$, and $100.0 \mathrm{~g} / \mathrm{L}$ of glucose and acetoin synthesis was measured during the course of growth.

On changing the glucose concentration from $2.5 \mathrm{~g} / \mathrm{L}$ to $100 \mathrm{~g} / \mathrm{L}$, a nonlinear increase in acetoin synthesis (from 
TABLE 2: Variation in titers of pyruvate and acetoin by change of initial glucose concentration.

\begin{tabular}{|c|c|c|c|c|c|}
\hline $\begin{array}{l}\text { Glucose } \\
(\mathrm{g} / \mathrm{L})\end{array}$ & $\begin{array}{l}\text { Time of maximum } \\
\text { acetoin yield }(\mathrm{h})\end{array}$ & $\begin{array}{c}\text { Maximum acetoin* } \\
(\mathrm{g} / \mathrm{L})\end{array}$ & $\begin{array}{c}\text { Pyruvate* } \\
(\mathrm{mg} / \mathrm{L})\end{array}$ & $\begin{array}{l}\text { Residual glucose at } \\
\text { maximum } \\
\text { acetoin yield }{ }^{*}(\mathrm{~g} / \mathrm{L})\end{array}$ & $\begin{array}{c}\text { Yield } \\
\left(\mathrm{mol} \cdot \mathrm{mol}^{-1}\right)^{*}\end{array}$ \\
\hline 2.5 & 28 & $0.08 \pm 0.06$ & 5 & $0.6 \pm 0.09$ & 0.06 \\
\hline 5 & 40 & $0.2 \pm 0.03$ & 50 & $0.8 \pm 0.11$ & 0.08 \\
\hline 10 & 40 & $0.4 \pm 0.08$ & 58 & $3 \pm 0.08$ & 0.08 \\
\hline 20 & 75 & $0.71 \pm 0.05$ & 172 & $5 \pm 0.26$ & 0.07 \\
\hline 50 & 125 & $1.4 \pm 0.10$ & 2800 & $12 \pm 1.26$ & 0.05 \\
\hline 100 & 156 & $2.7 \pm 0.12$ & 3500 & $23 \pm 1.96$ & 0.05 \\
\hline
\end{tabular}

${ }^{*}$ Time of maximum acetoin accumulation.

0.05 to $2.7 \mathrm{~g} / \mathrm{L}$ ) was observed. A maximum acetoin yield of $\sim 0.08 \mathrm{~mole} / \mathrm{mole}$ was observed for 5 and $10 \mathrm{~g} / \mathrm{L}$ glucose addition. On the contrary, a decrease in acetoin yield to $0.05 \mathrm{~mole} / \mathrm{mole}$ was observed on using 50 and $100 \mathrm{~g} / \mathrm{L}$ of glucose. An increase in glucose concentration (10-100 g/L) results in an increase in pyruvate accumulation from 57 to $3500 \mathrm{mg} / \mathrm{L}$. Moreover, an increase in glucose concentration also leads to shifts in time of maximum acetoin accumulation from 25 to $156 \mathrm{hr}$. The accumulation of pyruvate, residual glucose, and shift into the time point corresponding to maximum acetoin yield all suggest that efficiency of acetoin synthesis process decreases from glucose condition $10 \mathrm{~g} / \mathrm{L}$ onwards (Table 2). A $10 \mathrm{~g} / \mathrm{L}$ glucose level ensures an optimum acetoin yield and further studies have been performed at this level of carbon source.

3.2. Effect of Temperature. The effect of temperature on growth and secondary metabolite production is not universal. Synthesis of antibiotic production is highly dependent on temperature in Streptomyces sp. [18]. Contrariwise, in Bacillus licheniformis, acetoin synthesis is not dependent on temperature [10]. However, B. subtilis growth is affected by temperature. The influence of temperature on acetoin production by B. subtilis is yet not reported. B. subtilis was therefore grown at various temperatures $(25,30,37$, and $42^{\circ} \mathrm{C}$ ) and acetoin accumulation and growth were estimated keeping other culture conditions constant.

An average cell density of $\mathrm{OD}_{600} \sim 3.2$ was observed at 30,37 , and $42^{\circ} \mathrm{C}$. However, a substantial ( 37\%) reduction of growth was observed at $25^{\circ} \mathrm{C}$. Maximum acetoin accumulation was observed to be $0.41 \mathrm{~g} / \mathrm{L}$ at $37^{\circ} \mathrm{C}$. However, in comparison to $37^{\circ} \mathrm{C}, 70,60$, and $40 \%$ reduction in acetoin accumulation were observed at 25,30 , and $42^{\circ} \mathrm{C}$, respectively (Figure 1). Variation in acetoin concentration by changing the cultivation temperature suggests that acetoin synthesis is temperature dependent in B. subtilis.

3.3. Effect of $p H$. An external $\mathrm{pH}$ shift in turn affects the transcription profile of genes globally and acidic cultivation condition leads to the induction of alsSD in B. subtilis $[19,20]$. However, effect of external $\mathrm{pH}$ for acetoin accumulation has not been reported yet. To elucidate the effect of $\mathrm{pH}$ on acetoin synthesis, Bacillus subtilis was grown in minimal medium at various $\mathrm{pH}$ values from 4.5 to 9.5. Bacillus subtilis could not

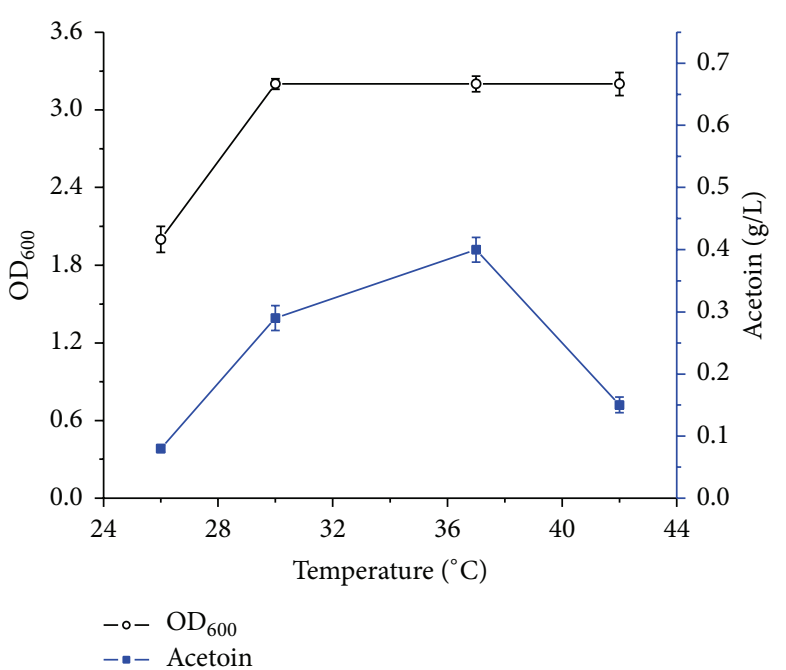

FIGURE 1: Effect of cultivation temperature on growth and acetoin synthesis by Bacillus subtilis.

survive acidic $\mathrm{pH}$ of 4.5. A comparable growth of $\mathrm{OD}_{600} \sim 3.3$ at $\mathrm{pH}$ 5.5-9.5 suggests that $\mathrm{pH}$ does not affect the growth of organism (data not shown).

A maximum of $0.42 \mathrm{~g} / \mathrm{L}$ of acetoin was observed at $\mathrm{pH}$ 7.5. In comparison to $\mathrm{pH} 7.5$, a $20 \%$ decrease was observed at acidic $\mathrm{pH}$ (5.5 and 6.5). However, $20 \%$ and $75 \%$ decrease in acetoin accumulation were observed at basic $\mathrm{pH} 8.5$ and 9.5, respectively (Figure 2). A lower acetoin accumulation in basic medium is due to expression of acetoin catabolic genes in alkaline conditions [20].

So, recommended $\mathrm{pH}$ for acetoin accumulation is 7.5 that favors both biomass and acetoin accumulation.

3.4. Effect of Redox Status. A higher acetoin accumulation is the function of shift of metabolite flux from glucose to acetoin and decrease in acetoin utilization. As indicated earlier, acetoin is either converted to its biological analogues diacetyl and 2,3-butanediol or catabolized to synthesize acetate; the culture redox potential is important for both reactions [21]. Redox status of culture can be changed by varying the agitation speed. Bacillus subtilis therefore was grown at 50 , 100, 150, 200, and $250 \mathrm{rpm}$. 
TABLE 3: Comparison of ALS enzyme activities of BS7431 and BS7432 under IPTG induced and uninduced condition.

\begin{tabular}{lccc}
\hline Serial number & Sample name & $\begin{array}{c}\text { Average enzyme activity } \\
\text { (formation of 1 nmol of acetolactate per minute) }\end{array}$ & $\begin{array}{c}\text { Specific enzyme activity } \\
\text { (unit/mg of protein) }\end{array}$ \\
\hline 1 & BS7431-Un* & $3.6 \pm 0.16$ & $0.52 \pm 0.06$ \\
2 & BS7431-In & $4.50 \pm 0.12$ & $0.64 \pm 0.08$ \\
3 & BS7432-Un* & $6.75 \pm 0.12$ & $0.95 \pm 0.02$ \\
4 & BS7432- In $^{\#}$ & $34.5 \pm 0.16$ & $4.86 \pm 0.02$ \\
\hline
\end{tabular}

${ }^{*}$ Uninduced cells; ${ }^{*}$ induced cells.

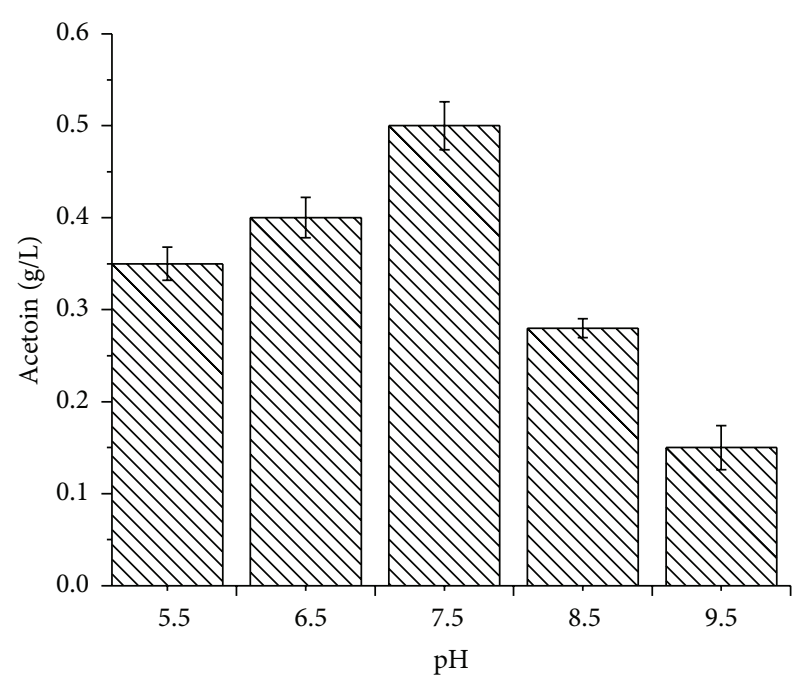

FIGURE 2: Effect of change of $\mathrm{pH}(5.5,6.5,7.5,8.5$, and 9.5) conditions on acetoin synthesis by Bacillus subtilis.

As expected, change in agitation speed is reflected in biomass production (3.2 and 1.7 at 250 and 50, resp.). Acetoin accumulation was observed to be maximal at $100 \mathrm{rpm}$ with a $50 \%$ decrease in 2,3-butanediol and $30 \%$ reduction in acetate synthesis, in comparison to other rpm conditions (Figure 3 ). An agitation rate of $100 \mathrm{rpm}$ is therefore optimal for acetoin accumulation.

3.5. Effect of Acetoin Synthesis Enzyme Activities (ALS and $A L D C$ ). Towards understanding the effect of levels of ALS and ALDC enzymes on acetoin biosynthesis, metabolite patterns were compared for Bacillus subtilis 168, strains lacking alsSD enzymes activities (deletion of alsR [14]), and strains having increased alsSD enzyme activities.

To confirm inducible expression of alsSD under IPTG control, ALS and ALDC activities were compared for BS7431 and BS7432 in presence and absence of IPTG [22]. A 6.3-fold increase in specific enzyme activity was observed on addition of IPTG at $46 \mathrm{hr}$ for BS7432 in comparison to BS7431. That suggests successful overexpression of alsSD operon under IPTG inducible control (Table 3).

A comparable $\mathrm{OD}_{600}$ of 3.1, 2.9, and 3.2 was observed for 168, BSIP1194, and BS7432 that suggest that level of ALS activities does not likely have an effect on viability of cells. In absence of ALS activity, $2.9 \mathrm{~g} / \mathrm{L}$ of glucose and $0.5 \mathrm{~g} / \mathrm{L}$ pyruvate were observed. However, none is observed for 168

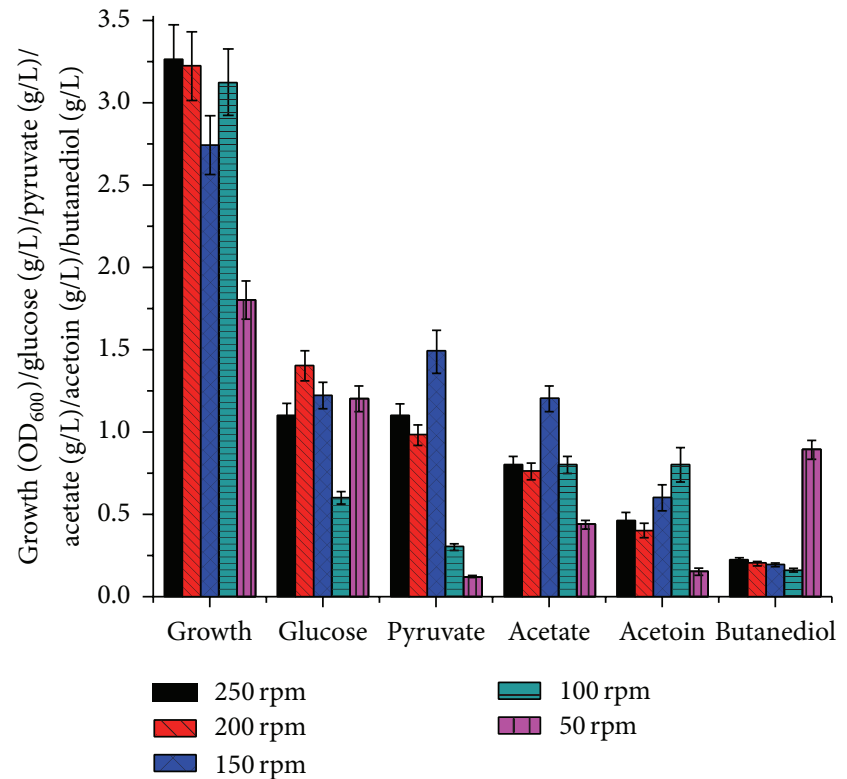

FIGURE 3: Effect of change in aeration $(50,100,150,200$, and $250 \mathrm{rpm})$ on biomass $\left(\mathrm{OD}_{600}\right)$, glucose, pyruvate, acetate, acetoin, and 2,3-butanediol. Data presented here is at maximum acetoin synthesis.

and BS7432 that suggests that levels of ALS affect glucose and pyruvate assimilation. Probable reason for residual glucose and accumulated pyruvate is inefficient metabolism in absence of functional alsSD. A 30\% enhancement in acetate accumulation (Figure 4) was observed in BSIP1194 that could be a result of shift of major pyruvate towards acetate synthesis in absence of acetoin biosynthetic pathway.

As acetate and 2,3-butanediol are the products of acetoin catabolism, an increase of acetoin biosynthesis is reflected in $50 \%$ increase in acetate and $40 \%$ increase in acetate (Figure 4). Increase of ALS and ALDC enzyme activities causes an $80 \%$ increase in accumulation of acetoin ( 0.5 of 168 and 1.2 in BS7432).

As only $10 \mathrm{mg} / \mathrm{L}$ of pyruvate was observed at maximum acetoin biosynthesis in BS7432, the reason of increased acetoin synthesis could be due to efficient utilization of pyruvate towards acetoin synthesis [23]. To reconfirm this, BS7431 and BS7432 were grown in medium conditions where residual glucose and accumulated pyruvate remain in growth medium (TSS $+20 \mathrm{~g} / \mathrm{L})$ and change in glucose (Figure 5(a)), biomass (Figure 5(b)), pyruvate (Figure 5(c)), acetoin (Figure 5(d)), 
TABLE 4: Comparison of acetoin yield, specific acetoin production, and maximum possible change in acetoin accumulation by variation of glucose, pyruvate, temperature, $\mathrm{pH}$, aeration, and acetoin synthesis enzyme.

\begin{tabular}{|c|c|c|}
\hline Physiological parameters & $\begin{array}{c}\text { Acetoin yield } \\
\text { (mole of acetoin produced/mole of glucose used) }\end{array}$ & $\begin{array}{l}\% \text { maximum possible change } \\
\text { in acetoin accumulation }\end{array}$ \\
\hline \multicolumn{3}{|l|}{ Glucose (g/L) } \\
\hline 2.5 & 0.004 & \multirow{3}{*}{32.0} \\
\hline 5 & 0.02 & \\
\hline 10 & 0.081 & \\
\hline \multicolumn{3}{|l|}{ Temperature } \\
\hline 25 & 0.020 & \multirow{3}{*}{30.1} \\
\hline 37 & 0.101 & \\
\hline 42 & 0.024 & \\
\hline \multicolumn{3}{|l|}{$\mathrm{pH}$} \\
\hline 5.5 & 0.071 & \multirow{3}{*}{38.5} \\
\hline 7.5 & 0.108 & \\
\hline 9.5 & 0.051 & \\
\hline \multicolumn{3}{|l|}{ Aeration (rpm) } \\
\hline 50 & 0.040 & \multirow{3}{*}{49.8} \\
\hline 100 & 0.143 & \\
\hline 250 & 0.102 & \\
\hline \multicolumn{3}{|l|}{ ALS and ALDC } \\
\hline 168 & 0.107 & \multirow{2}{*}{80.3} \\
\hline BS7432 & 0.245 & \\
\hline
\end{tabular}

${ }^{*}$ Percentage of the highest acetoin accumulation is calculated as $\{$ highest acetoin titre $(\mathrm{g} / \mathrm{L})-$ lowest acetoin titre $(\mathrm{g} / \mathrm{L}) /$ highest acetoin titre $(\mathrm{g} / \mathrm{L})\} * 100$.

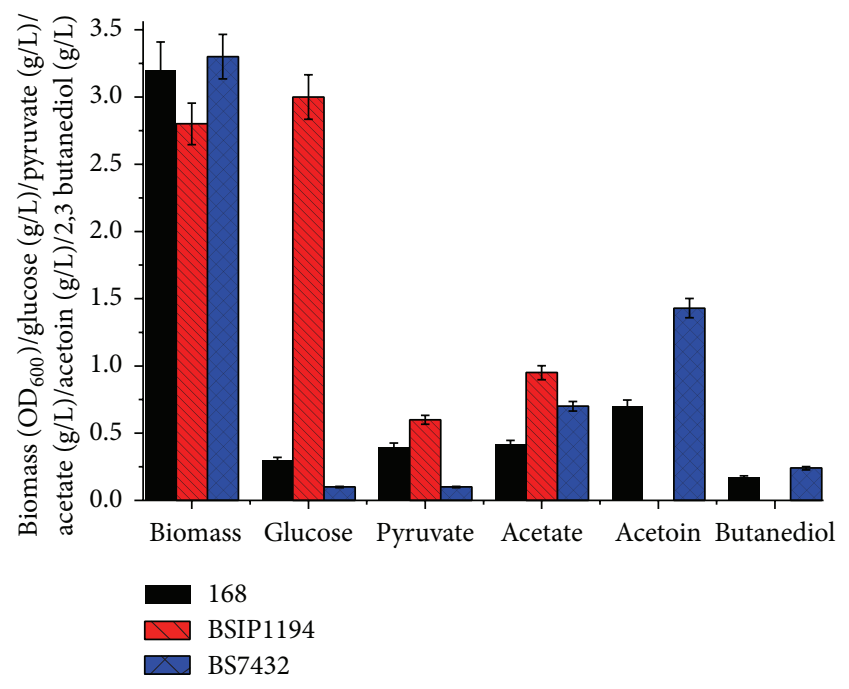

FIGURE 4: Comparative measurement for change in biomass, glucose, pyruvate, acetate, acetoin, and 2,3-butanediol for 168, BSIP1194, and BS7432. Data presented here is at maximum acetoin synthesis.

acetate (Figure 5(e)), and 2,3-butanediol (Figure 5(f)) was measured.

Expression of alsSD did not cause any change on growth (Figure 5(b)). There was no residual glucose which remains in the medium (Figure 5(a)). Additionally, in opposition to BS7431, in BS7432, all the pyruvate got exhausted by the end of $70 \mathrm{hr}$. These results strengthen the hypothesis of involvement of alsSD in efficient utilization of pyruvate and glucose towards acetoin synthesis. A maximum of $1.9 \mathrm{~g} / \mathrm{L}$ of acetoin accumulation was observed due to shift of flux from unused glucose and pyruvate (Figure 5(c)) [23]. Interestingly, expression of alsSD caused a $30 \%$ elevation in acetate level. Probably, elevated level is the product of acetoin catabolism.

\section{Conclusions}

The effect of glucose concentration, temperature, $\mathrm{pH}$, agitation, and enzyme amount was investigated on acetoin synthesis by Bacillus subtilis 168 in minimal medium. Growth of Bacillus subtilis is affected by $\mathrm{pH}$, temperature, and agitation. However, synthesis of byproducts (acetate and 2,3butanediol) depends on agitation and $\mathrm{pH}$ of cultivation medium. By optimizing physiological conditions (glucose concentration, $\mathrm{pH}$, temperature, and agitation), a maximum of $75 \%$ enhancement in acetoin yield was achieved (Table 4 ).

A maximum of $80 \%$ enhancement in acetoin accumulation was achieved by increasing ALS and ALDC enzyme activities. Increase in these enzyme activities is affected by efficient utilization of pyruvate towards acetoin synthesis (Table 4).

Comparable amplitude of change in acetoin yields by physiological variables and genotype changes suggests that optimal physiological conditions are equally important as that of genotype constituent. 


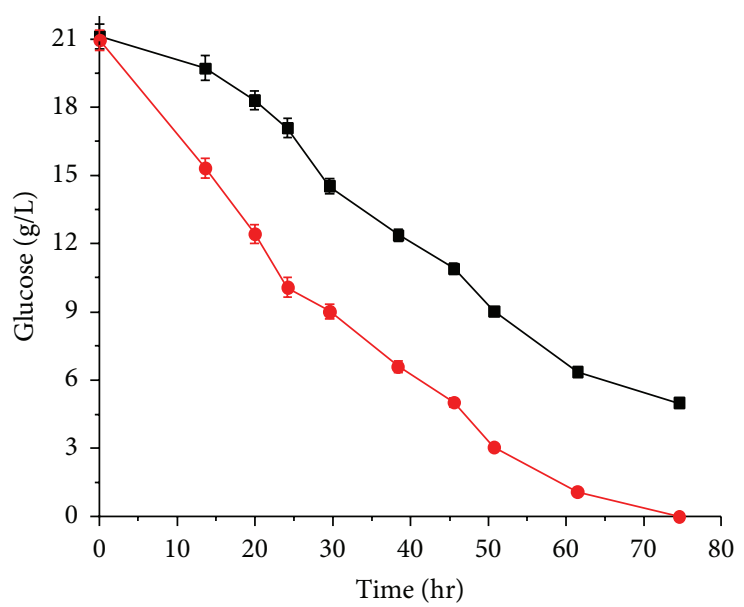

(a)

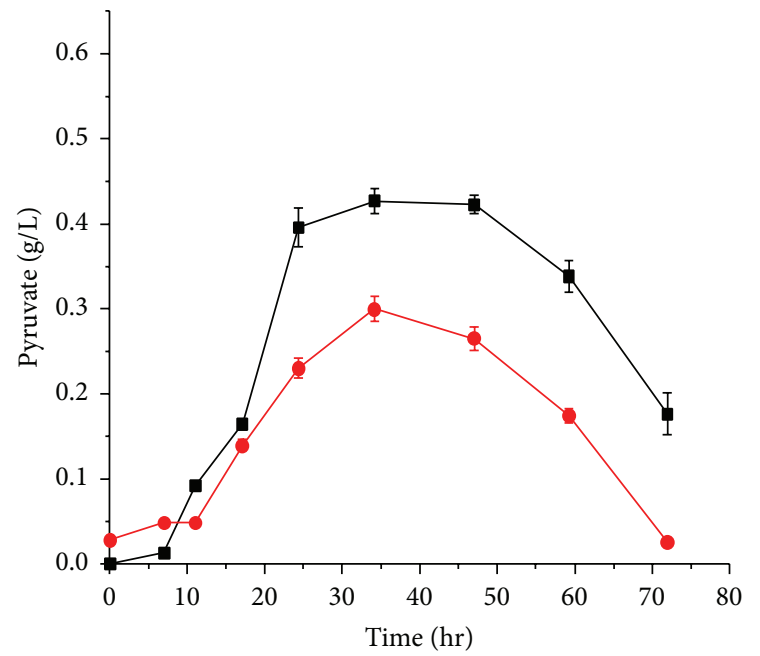

(c)

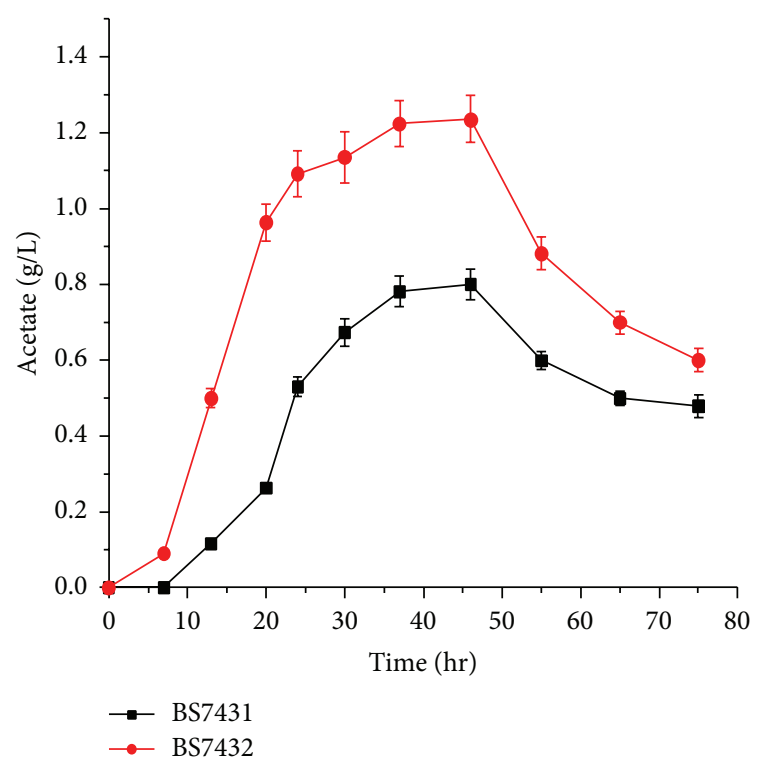

(e)

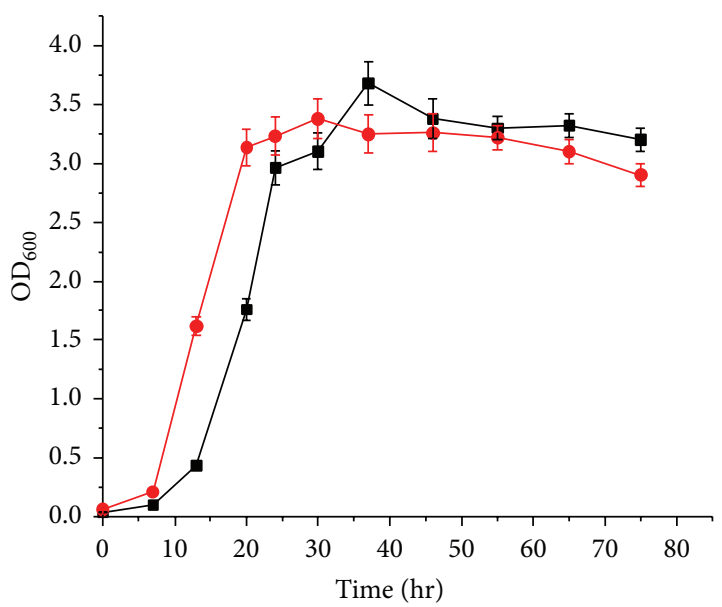

(b)

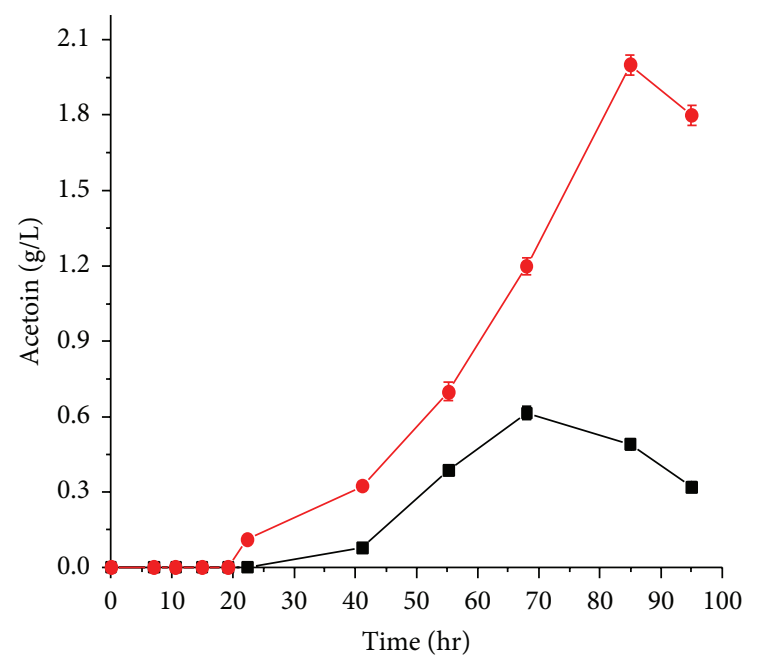

(d)

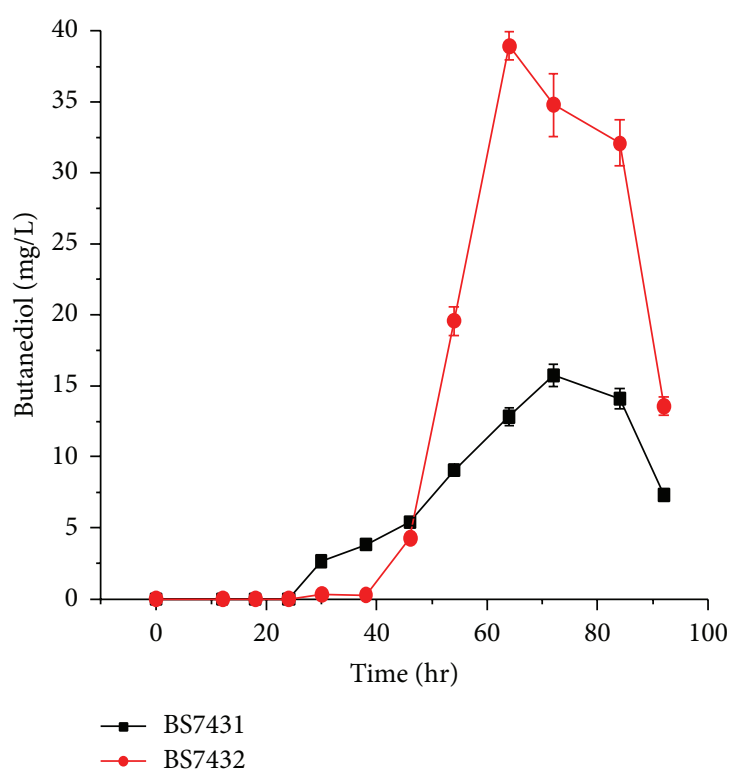

(f)

Figure 5: Comparative measurement of (a) biomass, (b) glucose, (c) pyruvate, (d) acetate, (e) acetoin, and (f) 2,3-butanediol for BS7432 with BS7431 at $\mathrm{pH} 7.5$ by BS7431 and BS7432. 
Based on these results, we conclude that, to maximize acetoin accumulation, it is important to control physiological variables as well as genotype constituents to ensure efficient pyruvate metabolism towards acetoin.

This methodology thus can become a guideline and useful tool to the large scientific and industrial communities that are developing methods for accumulating acetoin.

\section{Conflict of Interests}

The authors declare that there is no conflict of interests regarding the publication of this paper.

\section{Acknowledgment}

The authors wish to acknowledge Council for Scientific and Industrial research, India (F. no. 10-2(5)/2006(ii)-E.U.II), for fellowship to Pratibha Sharma.

\section{References}

[1] Z. Xiao and P. Xu, "Acetoin metabolism in bacteria," Critical Reviews in Microbiology, vol. 33, no. 2, pp. 127-140, 2007.

[2] E. B. Collins, "Biosynthesis of flavor compounds by microorganisms," Journal of Dairy Science, vol. 55, pp. 1022-1028, 1972.

[3] M. C. Renna, N. Najimudin, L. R. Winik, and S. A. Zahler, "Regulation of the Bacillus subtilis alsS, alsD, and alsR genes involved in post-exponential-phase production of acetoin," Journal of Bacteriology, vol. 175, no. 12, pp. 3863-3875, 1993.

[4] S. Atsumi, Z. Li, and J. C. Liao, "Acetolactate synthase from Bacillus subtilis serves as a 2-ketoisovalerate decarboxylase for isobutanol biosynthesis in Escherichia coli," Applied and Environmental Microbiology, vol. 75, no. 19, pp. 6306-6311, 2009.

[5] D. Mayer, V. Schlensog, and A. Bock, "Identification of the transcriptional activator controlling the butanediol fermentation pathway in Klebsiella terrigena," Journal of Bacteriology, vol. 177, no. 18, pp. 5261-5269, 1995.

[6] F. Bernd Oppermann, A. Steinbüchel, and H. G. Schlegel, "Utilization of methylacetoin by the strict anaerobe Pelobacter carbinolicus and consequences for the catabolism of acetoin," FEMS Microbiology Letters, vol. 55, no. 1, pp. 47-52, 1988.

[7] S. Klumpp, Z. Zhang, and T. Hwa, "Growth rate-dependent global effects on gene expression in bacteria," Cell, vol. 139, no. 7, pp. 1366-1375, 2009.

[8] T. K. Kirk, E. Schultz, and W. J. Connors, "Influence of culture parameters on lignin metabolism by Phanerochaete chrysosporium," Archives of Microbiology, vol. 117, no. 3, pp. 277285, 1978.

[9] K. V. Ramana, A. Tomar, and L. Singh, "Effect of various carbon and nitrogen sources on cellulose synthesis by Acetobacter xylinum," World Journal of Microbiology and Biotechnology, vol. 16, no. 3, pp. 245-248, 2000.

[10] P. Perego, A. Converti, and M. Del Borghi, "Effects of temperature, inoculum size and starch hydrolyzate concentration on butanediol production by Bacillus licheniformis," Bioresource Technology, vol. 89, no. 2, pp. 125-131, 2003.

[11] G. M. Vignolo, M. N. Kairuz, A. A. P. Ruiz Holgado, and G. Oliver, "Influence of growth conditions on the production of lactocin 705, a bacteriocin produced by Lactobacillus casei CRL 705," Journal of Applied Bacteriology, vol. 78, no. 1, pp. 5-10, 1995.
[12] M. Wang, J. Fu, X. Zhang, and T. Chen, "Metabolic engineering of Bacillus subtilis for enhanced production of acetoin," Biotechnology Letters, vol. 34, pp. 1877-1885, 2012.

[13] P. Sharma and S. Noronha, "Systematic study of acuABC operon in Bacillus subtilis 168," in International Proceedings of Chemical, Biological \& Environmenta (IPCBEE '12), vol. 31, pp. 17-21.

[14] H. C. Ramos, T. Hoffmann, M. Marino et al., "Fermentative metabolism of Bacillus subtilis: physiology and regulation of gene expression," Journal of Bacteriology, vol. 182, no. 11, pp. 3072-3080, 2000.

[15] W. W. Westerfeld, "A colorimetric determination of blood acetoin," The Journal of Biological Chemistry, vol. 161, pp. 495$502,1945$.

[16] H.-M. Blencke, G. Homuth, H. Ludwig, U. Mäder, M. Hecker, and J. Stülke, "Transcriptional profiling of gene expression in response to glucose in Bacillus subtilis: regulation of the central metabolic pathways," Metabolic Engineering, vol. 5, no. 2, pp. 133-149, 2003.

[17] M. Huang, F. B. Oppermann-Sanio, and A. Steinbüchel, "Biochemical and molecular characterization of the Bacillus subtilis acetoin catabolic pathway," Journal of Bacteriology, vol. 181, no. 12, pp. 3837-3841, 1999.

[18] P. D. A. James, C. Edwards, and M. Dawson, "The effects of temperature, $\mathrm{pH}$ and growth rate on secondary metabolism in Streptomyces thermoviolaceus grown in a chemostat," Journal of General Microbiology, vol. 137, no. 7, pp. 1715-1720, 1991.

[19] T. Hornbæk, M. Jakobsen, J. Dynesen, and A. K. Nielsen, "Global transcription profiles and intracellular $\mathrm{pH}$ regulation measured in Bacillus licheniformis upon external pH upshifts," Archives of Microbiology, vol. 182, no. 6, pp. 467-474, 2004.

[20] J. C. Wilks, R. D. Kitko, S. H. Cleeton et al., "Acid and base stress and transcriptomic responses in Bacillus subtilis," Applied and Environmental Microbiology, vol. 75, no. 4, pp. 981-990, 2009.

[21] W.-B. Yu, S.-H. Gao, C.-Y. Yin, Y. Zhou, and B.-C. Ye, "Comparative transcriptome analysis of Bacillus subtilis responding to dissolved oxygen in adenosine fermentation," PLoS ONE, vol. 6, no. 5, Article ID e20092, 2011.

[22] H. D. Nguyen, Q. A. Nguyen, R. C. Ferreira, L. C. S. Ferreira, L. T. Tran, and W. Schumann, "Construction of plasmid-based expression vectors for Bacillus subtilis exhibiting full structural stability," Plasmid, vol. 54, no. 3, pp. 241-248, 2005.

[23] T. Kaneko, M. Takahashi, and H. Suzuki, "Acetoin fermentation by citrate-positive Lactococcus lactis subsp. lactis 3022 grown aerobically in the presence of hemin or $\mathrm{Cu}^{2+}$, Applied and Environmental Microbiology, vol. 56, no. 9, pp. 2644-2649, 1990. 

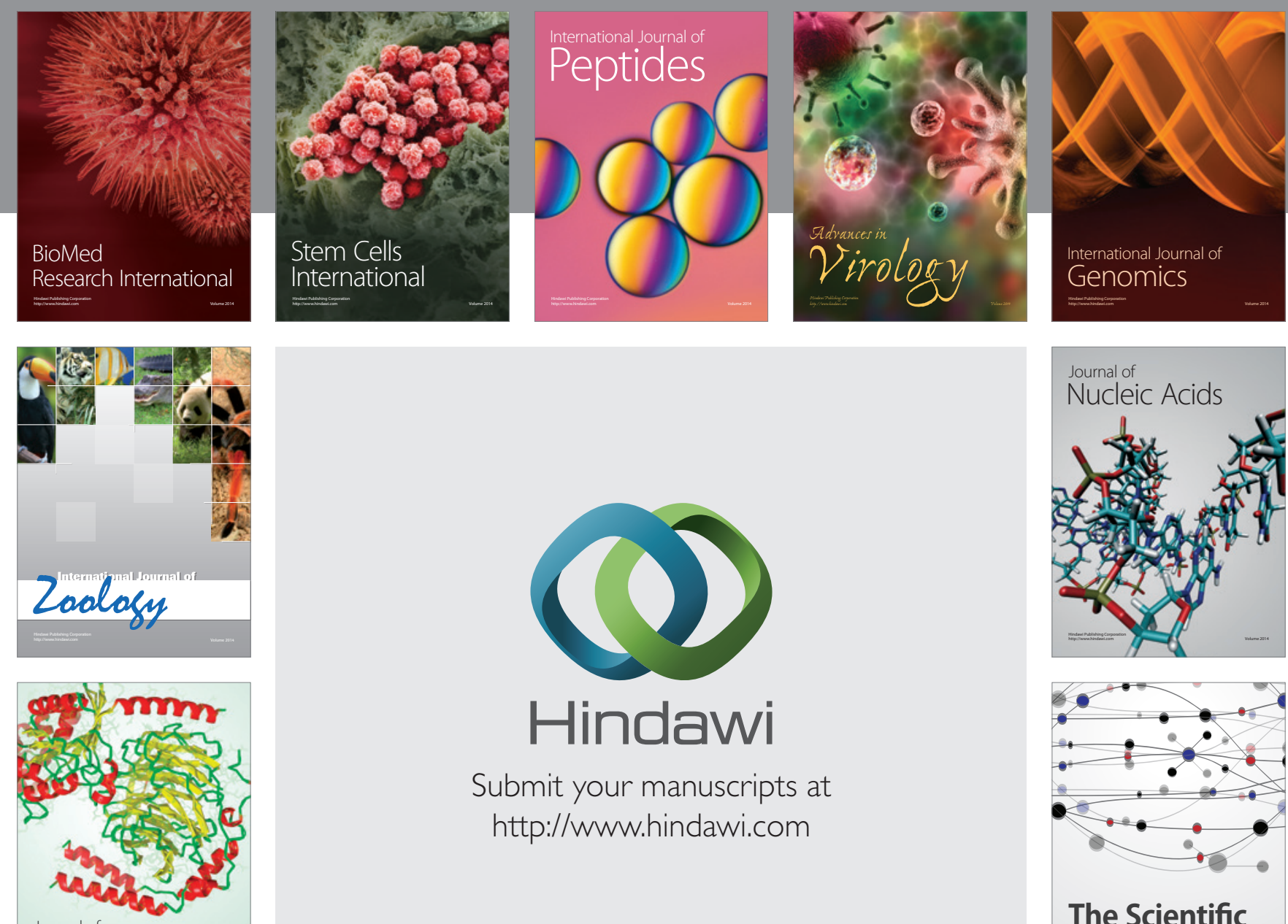

Submit your manuscripts at

http://www.hindawi.com

Journal of
Signal Transduction
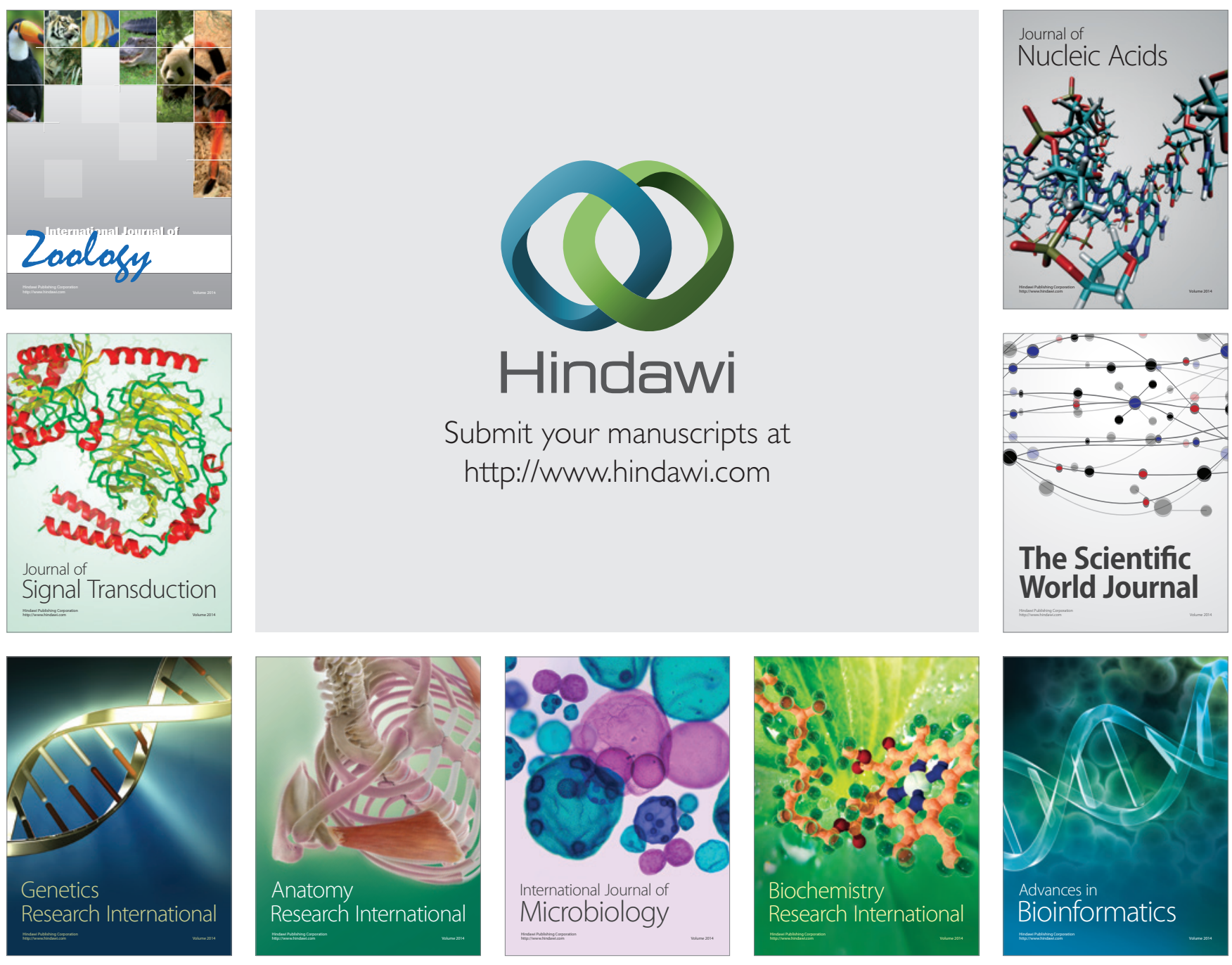

The Scientific World Journal
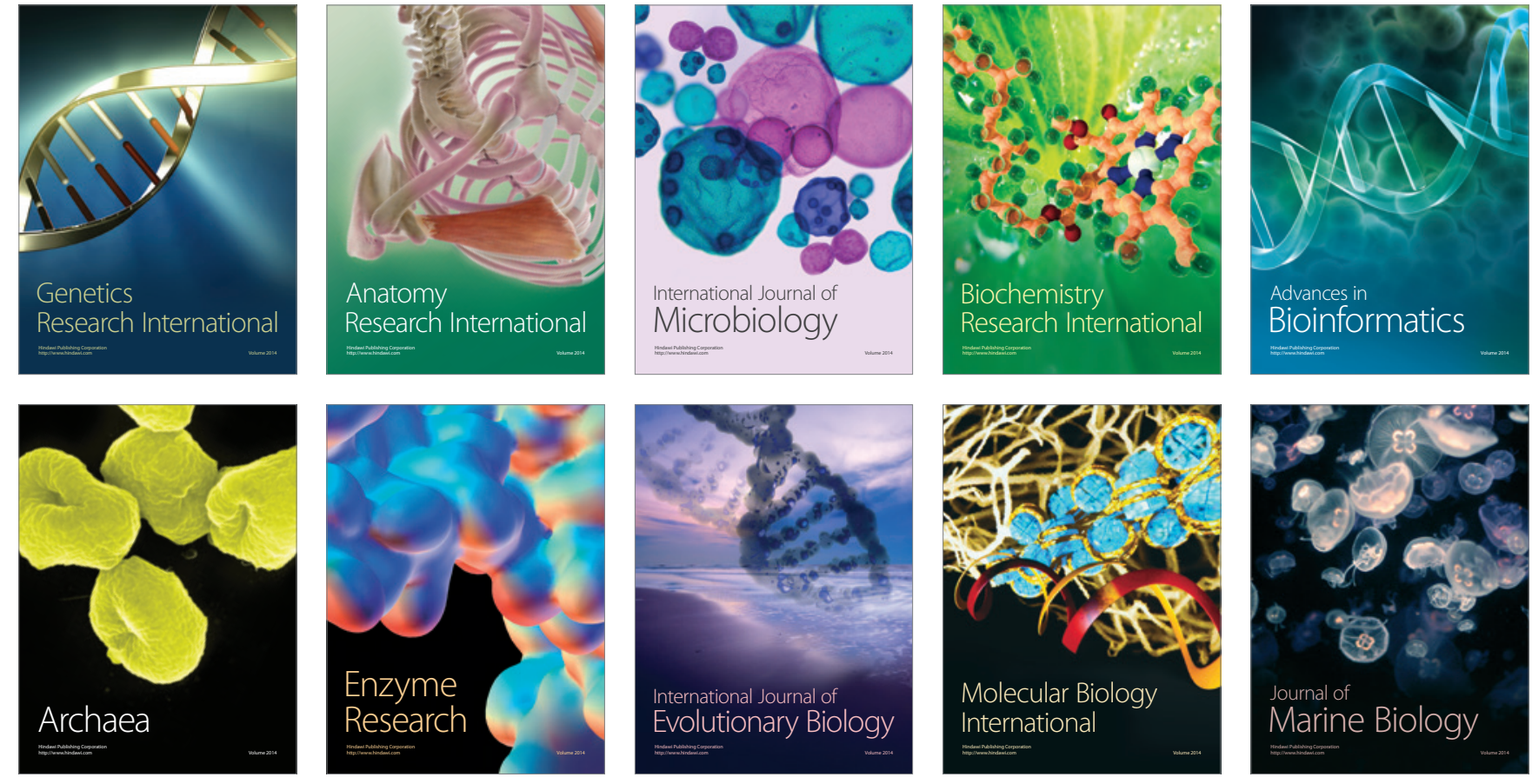